\title{
The Iranian Integrated Maternal Health Care Guideline Based on Evidence-Based Medicine and American Guidelines: A Comparative
} Study

\author{
Roghieh Kharaghani, ${ }^{1,}{ }^{*}$ Mohammad Shariati, ${ }^{2}$ Masud Yunesian, ${ }^{3}$ Afsaneh Keramat, ${ }^{4}$ and Alireza
}

\section{Moghisi ${ }^{5}$}

${ }^{1}$ Department of Midwifery, Faculty of Nursing and Midwifery, Zanjan University of Medical Sciences, Zanjan, IR, Iran

${ }^{2}$ Department of Community Medicine, Faculty of Medicine, Tehran University of Medical Sciences, Tehran, IR Iran

${ }^{3}$ Department of Environmental Health Engineering, Faculty of Public Health, Tehran University of Medical Sciences, Tehran, IR Iran

${ }^{4}$ Center for Health Related Social and Behavioral Sciences Research, Shahroud University of Medical Sciences, Shahroud, IR Iran

${ }^{5}$ Director of Program Assessment and Burden of Disease in Health Network System, Iranian Ministry of health and Medical Education, Tehran, IR Iran

"Corresponding author: Roghieh Kharaghani, Assistant Professor of Reproductive Health, Department of Midwifery, Faculty of Nursing and Midwifery, Zanjan University of Medical Sciences, Zanjan, IR Iran. Tel: +98-9125625984, Fax: +9-82165248501, E-mail: r.kharaghani@yahoo.com

Received 2016 February 04; Revised 2016 April 08; Accepted 2016 April 14.

\begin{abstract}
Background: There is a little consistency among prenatal care guidelines. An evidence-based guideline can be used to improve the quality of the mother and child health care. This study was designed to compare the consistency of the Iranian integrated maternal health care guideline with evidence-based prenatal care manuals and American guidelines.

Methods: In this comparative study, the Iranian guideline recommendations were compared with the content of American prenatal care according to obstetrics and gynecology recommendations of the U.S. preventive services task force and evidence-based prenatal care. The strength of the recommendations was assessed based on evidence-based medicine.

Results: In this study, 71 recommendations were compared in four parts. About 18.3 percent of the recommendations were consistent with all guidelines. Screening for group B streptococcus, performing chorionic villous sampling and amniocentesis for at risk women, and anomaly screening were not mentioned in the Iranian guideline. The Iranian guideline was consistent with the content of U.S. preventive services task force in 38\% of the recommendations, American Obstetricians and Gynecologists expert panel guidelines in $75.6 \%$ of the recommendations, and with evidence-based care in $66.2 \%$ of the recommendations.

Conclusions: Although there was a little consistency among guidelines, the Iranian guideline had a good consistency with the American guidelines and evidence-based care recommendations. Updating clinical tests and the prenatal screening part of the Iranian guideline based on the results of this study may increase the effectiveness of the prenatal care and ultimately improve the mother and child's health.
\end{abstract}

Keywords: Prenatal Care, Guideline, Evidence-Based Practice, Comparative Study

\section{Background}

In 2008, about343,000 mothers died due to pregnancy and childbirth complications (1). Although maternal mortality ratios (MMR) have decreased significantly in recent years, only 25 out of 181 countries are on the way to achieve a 75 percent reduction in MMR by 2015 , as one of the millennium development goals (MDG) (1). The incidence of maternal morbidity is much higher than the incidence of maternal mortality (2). Lynch et al. (3) showed that severe maternal morbidity occurs 26.5 times more than mortality in a developed country. Many maternal deaths, stillbirths, preterm births, and low birth weight cases are associated with inadequate prenatal care; therefore, by using adequate prenatal care, future complications can be reduced (4). The benefits of prenatal care may spread throughout the maternal life from one pregnancy to the next or even to the next generations (5).

Pregnancy is a physiological process in the human life; thus, any intervention should have well-known benefits for pregnant women and should also be acceptable. Prenatal care should enable women to make informed decisions based on their needs and discuss all their concerns with health care professionals. Prenatal care guidelines can help identify the best interventions for all uncomplicated normal pregnancies in primary health care settings and provide evidence-based information for health care professionals and pregnant women in special situations (6). There is not sufficient evidence about the effectiveness of the Iranian prenatal care guideline, but Tayebi et al. (7) showed that inadequate prenatal care caused $36 \%$ increase in the preterm labor rate and $8 \%$ increase in the low birth 
weight rate.

The results of applied research are employed in the clinical practice through knowledge translation as clinical guidelines to be used by medical and health professionals. This approach increases the application of evidencebased medicine in policy and decision making. It also can change attitude, practice, and behavior of health system organizations in the direction of knowledge-based health system. The final users of these services are clients (8). There are multiple guidelines for prenatal care in different countries, but these guidelines are not consistent in many recommendations $(9,10)$. Moreover, in many cases, documented evidence in medical research is not used in clinical practice (11).

A comparative study is a research methodology or process in which two or more variables are assessed to describe and explain the similarities and differences of data in order to achieve probable new interpretations and generalizations (12). Prenatal care guidelines have been compared in different countries by using this method $(9,10)$.

In Iran, the Iranian integrated maternal health care guideline is a guide for midwives and general practitioners in the health care centers. The cares start before pregnancy and continues during the pregnancy and postpartum periods (13). Despite little consistency among prenatal care guidelines, no study has assessed the consistency of the Iranian guideline with the available evidence, yet. According to our previous study, American pregnancy surveillance systems were the most appropriate ones for being adapted in Iran (14), so these guidelines could be appropriate for comparative assessment of Iranian prenatal guideline.

\section{Objectives}

This study aimed to determine the consistency of the Iranian protocol with evidence-based prenatal care manuals and American guidelines.

\section{Methods}

In this comparative study, "The Iranian national program on safe motherhood, integrated care on mother's health" (13) was compared to "caring for our future: the content of prenatal care: a report of the public health service expert panel on the content of prenatal care" (15), "The guide to clinical preventive Services, recommendations of the U.S. preventive services task force" (16), and "Evidencebased prenatal care, Part I: General prenatal care and counseling issues", "part II: Third-trimester care and prevention of infectious policy", and ""prenatal screening for down syndrome, trisomy 18 and open neural tube” (17-19).
The method used by Haertsch et al. (10) was applied to provide a list of recommended interventions in prenatal care. All protocols were studied and compared as follows. Recommended interventions for low-risk pregnancies were included and the recommendations for highrisk pregnancies such as multiple pregnancies, Rh Isoimmunization, and other risk factors were excluded. There were 71 recommendations in four parts including: general health screening and health promotion, prenatal care organization, clinical tests and prenatal screening, and special education for pregnancy.

Specific recommendations were integrated with more general recommendations whenever possible, and the details were described in the table footnotes if integration was not possible. The recommended time of interventions was described as preconception, first, second, and third trimester, throughout the pregnancy or without a specific time. For example, the code 1 indicated that the recommendation should be performed in the first trimester. In the Iranian guideline, preconception care is integrated with prenatal care; therefore, the code 0 was used for recommendations in this period. The time was specified in most of the recommended interventions.

Finally, the strength of the recommendations was determined by the labels $\mathrm{A}, \mathrm{B}$, and $\mathrm{C}$ when the recommendations were based on evidence-based medicine (17-19); label A indicated that the recommendation was based on consistent, good-quality patient-oriented evidence; label B indicated that the recommendation was based on inconsistent or limited-quality patient-oriented evidence; and label $\mathrm{C}$ indicated that the recommendation was based on consensus, disease-oriented evidence, usual practice, opinion, or case series (20). This study was approved and funded by Deputy of research and technology, Shahroud University of Medical Sciences (Code: 92168)

\section{Results}

Overall, 71 recommendations were extracted and compared. They were divided into four parts as follows: 20 in general health screening and health promotion, 6 in prenatal care organization, 37 in clinical tests and prenatal screening and 8 in special education for pregnancy.

\subsection{Details of Different Parts of Protocols}

Tables 1 to 4 show detailed comparisons between the guidelines. All label A and B evidence- based recommendations were mentioned in the Iranian guideline. Level C recommendations that were not mentioned in the Iranian guideline, included the following: discussion about exercise patterns in Table 1, collection of menstrual and gyne- 
cological history, determination of blood group antibodies, screening for group B streptococcus, performing CVS and amniocentesis for high risk women and screening for 13, 18 and 21 trisomies in Table 3, and education about future tests in Table 4. All evidence-based recommendations in Table 2 were mentioned in the Iranian guideline.

\subsection{Consistency of Recommendations Between Protocols}

For "health screening and health promotion during pregnancy", 3 recommendations were not included in any of the protocols and three protocols had 40\% consistent recommendations. Also for "prenatal care organization", two protocols had 50\% consistent recommendations. Regarding "clinical tests and prenatal screening", three protocols had $32.4 \%$ consistent recommendations, and for "special education for pregnancy", two protocols had 37.5\% consistent recommendations. In total, $33.8 \%$ of the recommendations were consistent among the three protocols and only 13 out of 71 recommendations (18.3\% of the recommendations) were present in all four protocols (Table 5). The last three columns of the Table 5 demonstrate the consistency of the Iranian guideline with other protocols. The Iranian guideline was consistent with evidence-based care and American Obstetricians and Gynecologists expert panel in $80 \%$ of the cases in "health screening and health promotion". It was consistent with American Obstetricians and Gynecologists expert panel in $66.6 \%$ of the cases in "prenatal care organization" and in $75.7 \%$ of the cases in "clinical tests and prenatal screening".

The Iranian guideline was consistent with evidencebased care and American obstetricians and gynecologists expert panel in "special education for pregnancy" in $62.5 \%$ of the cases. In total, the Iranian guideline was consistent with American obstetricians and gynecologists expert panel in $74.6 \%$ of cases and with evidence- based care in $66.2 \%$ of cases.

\section{Discussion}

The results of this study showed that $18.3 \%$ of recommendations were consistent in all 4 protocols, and the Iranian guideline in more than $60 \%$ of the recommendations was consistent with American obstetricians and gynecologists expert panel and evidence-based care. There were all labels A and B evidence-based recommendations in the Iranian guideline, although there were not some label C scientific based recommendations.

Despite the fact that protocols contained similar recommendations in some cases, there were differences in their details. For example, the number of prenatal visits was specified in four protocols, but varied from 7 to 11 visits. In the Iranian guideline, 8 visits have been recommended. Some studies have reported the number of prenatal care visits has no effect on reducing perinatal mortality and costs; therefore, the number of prenatal care visits has reduced in some protocols. However, recent studies indicate that it may cause complications for mother and fetus. More frequent prenatal care visits make it possible to find more cases with complications that occur in the third trimester of pregnancy, such as preeclampsia, fetal growth restriction, and unexplained fetal death $(21,22)$.

Although the use of evidence-based perinatal care can be effective (23), prenatal education has not been well researched in the studies. Also, contrary to the advice of existing evidence, education does not have woman-centered focus, thus behavior changes do not seem to be fit. Education in the prenatal care could provide opportunities for health promotion and harm reduction, which have long-term impact on healthy behaviors of the mother and her family. Guidelines have clearly defined the time of offering many educations but it is important that issues related to protection, comfort, curiosity, health, and welfare of women be offered in a systematic manner to ensure emphasizing them throughout pregnancy (24-26). In many parts of the world, education programs are emphasized in group or individual sessions, but Gagnon and Sandall in a Cochrane review published in 2007 demonstrated that high quality evidence did not exist for some educational needs of women such as birth and parenting (27). In the Iranian guideline, educational needs of women have been considered, but it could have more details such as the use of safety belt.

The reason for different prenatal care recommendations in different protocols can be related to the different bases of protocols; for example, some protocols are based on study results (16-19) and others are based on expert opinions $(13,15)$. Moreover, differences in economic status and healthcare systems of countries as well as publication dates may play important roles in this regard. We require strategies that consider economy, clients, and the country's circumstances to develop consistent and evidence-based recommendations for health care professionals. Such guidelines will help the community, clinicians, governmental agencies, and research bodies to provide consistent performance, to reduce inappropriate interventions, and to improve the efficiency and effectiveness of the prenatal care (10).

The Iranian guideline was in good agreement with the principles of American Obstetricians and Gynecologists expert panel and evidence-based care, which is one of the strong points of this protocol and indicates the applicability of this protocol based on research evidence; however, some evidence-based recommendations did not involve in 
Table 2. Comparison of Prenatal Care/Organization ${ }^{\mathrm{a}, \mathrm{b}}$

\begin{tabular}{|c|c|c|c|c|c|}
\hline Recommendations & $\begin{array}{c}\text { Iranian Guideline } \\
2010\end{array}$ & $\begin{array}{c}\text { American Expert Panel } \\
1989\end{array}$ & $\begin{array}{c}\text { American Task Force } \\
2012\end{array}$ & $\begin{array}{c}\text { Evidence-Based Care, } \\
2005-2011\end{array}$ & Strength of Evidence \\
\hline $\begin{array}{l}\text { Mothers should carry } \\
\text { the record }\end{array}$ & 4 & - & - & - & - \\
\hline $\begin{array}{l}\text { Offer induction after } \\
41 \text { weeks of pregnancy }\end{array}$ & $3^{c}$ & - & - & 3 & A \\
\hline $\begin{array}{l}\text { Prenatal course } \\
\text { should be written in } \\
\text { the record }\end{array}$ & 0 and 4 & 4 & - & - & - \\
\hline $\begin{array}{l}\text { Refer for } \\
\text { complications of } \\
\text { pregnancy including } \\
\text { referral to a dentist or } \\
\text { hospital }\end{array}$ & 0 and 4 & 4 & - & - & - \\
\hline Prenatal visits & $4^{d}$ & $4^{e}$ & - & $4^{\mathrm{f}}$ & B \\
\hline $\begin{array}{l}\text { Describe prenatal care } \\
\text { that midwives, } \\
\text { general practitioners, } \\
\text { and obstetricians can } \\
\text { provide }\end{array}$ & 0 and 4 & 4 & - & 4 & A \\
\hline \multicolumn{6}{|c|}{$\begin{array}{l}\text { a } 0=\text { preconception; } 1=\text { first trimester; } 2=\text { second trimester; } 3=\text { third trimester; } 4=\text { through } \\
\text { the protocol. } \\
\text { b A, consistent, good-quality patient-oriented evidence; } B \text {, inconsistent or limited-quality pa } \\
\text { tice, opinion, or case series. } \\
{ }^{c} \text { After } 41 \text { weeks of pregnancy, the mother is referred. } \\
{ }^{d} 8 \text { visits for multiparous and nulliparous women. } \\
\text { e } 8 \text { visits for nulliparous and } 6 \text { visits for multiparous women until } 40 \text { weeks of pregnancy } \\
\mathrm{f}_{7} \text { to } 11 \text { visits. }\end{array}$} \\
\hline
\end{tabular}

Table 4. Comparison of Special Education for Pregnancy ${ }^{\mathrm{a}}$

\begin{tabular}{|c|c|c|c|c|c|}
\hline Recommendations & $\begin{array}{c}\text { Iranian Guideline } \\
2010\end{array}$ & $\begin{array}{c}\text { American Expert Panel } \\
1989\end{array}$ & $\begin{array}{c}\text { American Task Force } \\
2012\end{array}$ & $\begin{array}{c}\text { Evidence-Based Care, } \\
2005-2011\end{array}$ & Strength of Evidence \\
\hline $\begin{array}{l}\text { Changes in pregnancy } \\
\text { and discomfort }\end{array}$ & 4 & 4 & - & - & - \\
\hline Breastfeeding & 2 and 3 & 2 and 3 & 4 & 5 & B \\
\hline Labor and birth plans & 4 & 2 and 3 & - & 5 & $\mathrm{C}$ \\
\hline $\begin{array}{l}\text { Birth education } \\
\text { Classes }\end{array}$ & 4 & 2 and 3 & - & - & - \\
\hline Future tests & - & - & - & 5 & $\mathrm{C}$ \\
\hline $\begin{array}{l}\text { Symptoms, } \\
\text { complications, and } \\
\text { risks report }\end{array}$ & 4 & 4 & - & - & - \\
\hline The use of safety belts & - & $2^{\mathrm{b}}$ & - & - & - \\
\hline $\begin{array}{l}\text { Encouraging women } \\
\text { to seek information } \\
\text { on pregnancy and } \\
\text { birth }\end{array}$ & - & 4 & - & - & - \\
\hline
\end{tabular}

${ }^{\mathrm{a}} 0=$ preconception; 1 = first trimester; 2 = second trimester; $3=$ third trimester; 4 = through the pregnancy; $5=$ time and frequency is not specified; $-=$ not mention it in the A, consistent, good-quality patient-oriented evidence; B, inconsistent or limited-quality patient-oriented evidence; C, consensus, disease-oriented evidence, usual practice, opinion, or case series.

${ }^{\mathrm{b}}$ Including Infant car safety.

the Iranian protocol, which can be due to some differences in culture, health care systems, or medical education systems between Iran and the US. It seems that economic considerations play a role in not recommending some interventions such as screening for group B streptococcus, performing CVS, and amniocentesis for at risk women and screening for 13, 18, and 21 trisomies. Lack of skilled labora- tory personnel for triple and quad marker screening tests, equipment, and also skilled radiologists for measuring fetal neck thickness may also play a role in the absence of these recommendations. If the costs of the recommendations are covered by the insurance systems and the laboratory personnel and radiologists receive necessary training, adding these tests increases the value of the proto- 
Table 5. Comparison of Consistency of Recommendations Among Prenatal Care Protocols and the Consistency of the Iranian Guideline With Other Protocols ${ }^{\mathrm{a}}$

\begin{tabular}{|c|c|c|c|c|c|c|c|c|c|}
\hline $\begin{array}{l}\text { Recommendation } \\
\text { parts }\end{array}$ & $\begin{array}{l}\text { Total Recommen- } \\
\text { dations }\end{array}$ & Zero Protocol & One Protocol & Two Protocols & Three Protocols & Four Protocols & $\begin{array}{c}\text { American Expert } \\
\text { Panel } 1989\end{array}$ & $\begin{array}{c}\text { American Task } \\
\text { Force 2012 }\end{array}$ & $\begin{array}{l}\text { Evidence-Based } \\
\text { Care, 2005-2011 }\end{array}$ \\
\hline $\begin{array}{l}\text { General health } \\
\text { screening and } \\
\text { health promotion }\end{array}$ & 20 & $3(15)$ & $2(10)$ & $3(15)$ & $8(40)$ & $4(20)$ & $16(80)$ & $11(55)$ & $16(80)$ \\
\hline $\begin{array}{l}\text { Prenatal } \\
\text { care/organization }\end{array}$ & 6 & 0 & $1(16.7)$ & $3(50)$ & $2(33.3)$ & 0 & $4(66.6)$ & 0 & $3(50)$ \\
\hline $\begin{array}{l}\text { Clinical tests and } \\
\text { prenatal } \\
\text { screening }\end{array}$ & 37 & 0 & $7(18.9)$ & $10(27)$ & $12(32.4)$ & $8(21.6)$ & $28(75.7)$ & $12(32.4)$ & $23(62.2)$ \\
\hline $\begin{array}{l}\text { Special education } \\
\text { for pregnancy }\end{array}$ & 8 & 0 & $2(25)$ & $3(37.5)$ & $2(25)$ & 1(12.5) & $5(62.5)$ & $4(50)$ & $5(62.5)$ \\
\hline Total & 71 & $3(4.2)$ & $12(16.9)$ & $19(26.7)$ & $24(33.8)$ & $13(18.3)$ & $53(74.6)$ & $27(38)$ & $47(66.2)$ \\
\hline
\end{tabular}

col. Also, adding other recommendations including discussions about the pattern of exercise, rest, and sleep can result in better pregnancy outcomes. Updating the protocol at regular intervals based on the results of the latest studies, particularly on the basis of epidemiological surveillance systems in pregnancy, could increase the effectiveness of the prenatal care and ultimately improve the health of the mother and child.

\subsection{Conclusion}

The Iranian guideline had a good agreement with the evidence-based care recommendations. However, recommendations about screening for group B streptococcus, performing chorionic villous sampling and amniocentesis for at risk women, and anomaly screening were not included in Iranian protocol, which can be due to differences in culture, health care systems, or medical education systems between Iran and other countries. Updating clinical tests and some parts of the Iranian guideline such as the prenatal screening part at regular intervals based on the results of recent studies may increase the effectiveness of the prenatal care. Also, the establishment of pregnancy and child birth surveillance system is an essential component of evidence-based decision making system in this area, and could provide valuable maternal and child health information for updating the guideline (28). Therefore, it is highly recommended for health planners and policy makers to develop such surveillance system in Iran.

\section{References}

1. Hogan MC, Foreman KJ, Naghavi M, Ahn SY, Wang M, Makela SM, et al. Maternal mortality for 181 countries, 1980-2008: a systematic analysis of progress towards Millennium Development Goal 5. Lancet. 2010;375(9726):1609-23. doi: 10.1016/S0140-6736(10)60518-1. [PubMed: 20382417].

2. Maine D, McGinn T. Maternal Mortality and Morbidity. San Diego: Academic Press; 2000. pp. 395-403.

3. Lynch CM, Sheridan C, Breathnach FM, Said S, Daly S, Byrne B. Near miss maternal morbidity. Ir Med J. 2008;101(5):134-6. [PubMed: 18624257].
4. Cox RG, Zhang L, Zotti ME, Graham J. Prenatal care utilization in Mississippi: racial disparities and implications for unfavorable birth outcomes. Matern Child Health J. 2011;15(7):931-42. doi: 10.1007/s10995009-0542-6. [PubMed: 19943096].

5. Walford HH, Trinh S, Wiencrot A, Lu MC. What is the Role of Prenatal Care in Reducing Racial and Ethnic Disparities in Pregnancy Outcomes?. Springer; 2011. pp. 151-79.

6. National Institute for Health and Clinical Excellence . NICE clinical guideline, Antenatal care. Manchester: National Institute for Health and Clinical Excellence National Institute for Health and Clinical Excellence; 2010. Available from: www.evidence.nhs.uk.

7. Tayebi T, Zahrani ST, Mohammadpour R. Relationship between adequacy of prenatal care utilization index and pregnancy outcomes. Iran J Nurs Midwifery Res. 2013;18(5):360-6. [PubMed: 24403937].

8. Atchan M, Davis D, Foureur M. Applying a knowledge translation model to the uptake of the Baby Friendly Health Initiative in the Australian health care system. Women Birth. 2014;27(2):79-85. doi: 10.1016/j.wombi.2014.03.001. [PubMed: 24686049].

9. Hunt JM, Lumley J. Are recommendations about routine antenatal care in Australia consistent and evidence-based?. Obstetrical \& Gynecological Survey. 2002;57(10):652-4. doi: 10.1097/00006254200210000-00005.

10. Haertsch M, Campbell E, Sanson-Fisher R. What is recommended for healthy women during pregnancy? A comparison of seven prenatal clinical practice guideline documents. Birth. 1999;26(1):24-30. [PubMed: 10352052].

11. Buchan H. Gaps between best evidence and practice: causes for concern. Med J Aust. 2004;180(6 Suppl):48-9. [PubMed: 15012579].

12. Powell RR. Basic research methods for librarians, Contemporary studies in information management, policy, and services Information Management, Policy, and Services. Greenwich, Conn.: Ablex Publishing Corporation. 1997

13. Iranian Ministry of Health and Medical Education . Iranian National Program on Safe Motherhood, Integrated Care on Mother's Health, Outside hospital services Guide. 3 ed. Tehran: Iranian Ministry of Health and Medical Education; 2010.

14. Kharaghani R. Adaptation of Pregnancy Risk Assessment Monitoring System (PRAMS) and provide a model on it. Shahroud, Iran: Faculty of Nursing and Midwifery; .

15. Rosen MG. Caring for Our Future: The Content of Prenatal Care: a Report of the Public Health Service Expert Panel on the Content of Prenatal Care. Public Health Service, Department of Health and Human Services. 1989.

16. US preventive services task force . The Guide to Clinical Preventive Services, Recommendations of the U.S. Preventive Services Task Force. Agency for Healthcare research and quality, Advancing excellence in health care 2012. Available from: www.epss.ahrq.gov. 
17. Kirkham C, Harris S, Grzybowski S. Evidence-based prenatal care: Part I. General prenatal care and counseling issues. Am Fam Physician. 2005;71(7):1307-16. [PubMed: 15832534].

18. Kirkham C, Harris S, Grzybowski S. Evidence-based prenatal care: part II. Third-trimester care and prevention of infectious diseases. Am Fam Physician. 2005;71(8):1555-60. [PubMed: 15864896].

19. The British Columbia Prenatal Genetic Screening Program . Perinatal Services BC Obstetric Guideline, Prenatal Screening For Down Syndrome, Trisomy 18 and Open Neural Tube Defects Journal 2011. Available from: http://www.bcprenatalscreening.ca/sites/prenatal2/files/ GuidelineMarch.pdf.

20. Ebell MH, Siwek J, Weiss BD, Woolf SH, Susman J, Ewigman B, et al. Strength of recommendation taxonomy (SORT): a patient-centered approach to grading evidence in the medical literature. J Am Board Fam Pract. 2004;17(1):59-67. [PubMed: 15014055].

21. Hofmeyr GJ, Hodnett ED. Antenatal care packages with reduced visits and perinatal mortality: a secondary analysis of the WHO antenatal care trial - Comentary: routine antenatal visits for healthy pregnant women do make a difference. Reprod Health. 2013;10:20. doi: 10.1186/1742-4755-10-20. [PubMed: 23577750].

22. Vogel JP, Habib NA, Souza JP, Gulmezoglu AM, Dowswell T, Carroli G et al. Antenatal care packages with reduced visits and perinatal mor- tality: a secondary analysis of the WHO Antenatal Care Trial. Reprod Health. 2013;10:19. doi:10.1186/1742-4755-10-19. [PubMed: 23577700].

23. Turner T, Short J, Sea-Orchid Study Group . Barriers to and enablers of evidence-based practice in perinatal care in the SEA-ORCHID project. J Eval Clin Pract. 2013;19(4):591-7. doi: 10.1111/j.1365-2753.2011.01810.x. [PubMed: 22128845].

24. Gregory KD, Johnson CT, Johnson TR, Entman SS. The content of prenatal care. Update 2005. Womens Health Issues. 2006;16(4):198-215 doi: 10.1016/j.whi.2006.05.001. [PubMed: 16920524].

25. Roberts JE. Priorities in prenatal education.JOGNNurs. 1976;5(3):17-20. [PubMed: 1046483].

26. Hanson L, VandeVusse L, Roberts J, Forristal A. A critical appraisal of guidelines for antenatal care: components of care and priorities in prenatal education. J Midwifery Womens Health. 2009;54(6):458-68. doi:10.1016/j.jmwh.2009.08.002. [PubMed:19879518].

27. Gagnon AJ, Sandall J. Individual or group antenatal education for childbirth or parenthood, or both. Cochrane Database Syst Rev 2007(3):002869. doi: 10.1002/14651858.CD002869.pub2. [PubMed: 17636711].

28. Kharaghani R, Shariati M, Yunesian M, Keramat A, Moghisi A. Feasibility Study of the Pregnancy Risk Assessment Monitoring System in Iran. Iran J Public Health. 2014;43(12):1669-79. [PubMed: 26171360]. 
Table 1. Comparison of the Health Screening and Health Promotion During Pregnancy ${ }^{\mathrm{a}, \mathrm{b}}$

\begin{tabular}{|c|c|c|c|c|c|}
\hline Recommendations & $\begin{array}{c}\text { Iranian Guideline } \\
2010\end{array}$ & $\begin{array}{l}\text { American Expert } \\
\text { Panel } 1989\end{array}$ & $\begin{array}{l}\text { American Task Force } \\
2012\end{array}$ & $\begin{array}{c}\text { Evidence-Based Care, } \\
2005-2011\end{array}$ & Strength of Evidence \\
\hline $\begin{array}{l}\text { Job and income } \\
\text { security assessment } \\
\text { (including the } \\
\text { socioeconomic risks } \\
\text { of household size, } \\
\text { level of financial } \\
\text { resources and support } \\
\text { network) }\end{array}$ & - & 1 & - & - & - \\
\hline $\begin{array}{l}\text { Occupational and } \\
\text { environmental risk } \\
\text { assessment (job, } \\
\text { prolonged standing, } \\
\text { exposure to chemicals } \\
\text { and radiation) }\end{array}$ & 0 and 1 & 1 & - & 1 & B \\
\hline $\begin{array}{l}\text { Psychological risk } \\
\text { assessment (major life } \\
\text { events, stress and } \\
\text { anxiety, domestic } \\
\text { violence, and mental } \\
\text { illness) }\end{array}$ & 0 and 1 & 1 & 1 & - & - \\
\hline $\begin{array}{l}\text { Folic acid } \\
\text { supplementation ( } 0.4 \\
\text { to } 0.8 \text { mg per day, one } \\
\text { to three months } \\
\text { before pregnancy) }\end{array}$ & 0 and 4 & - & 0 and 4 & 0 and 1 & A \\
\hline $\begin{array}{l}\text { Maternal medical } \\
\text { history collection } \\
\text { (history of chronic } \\
\text { diseases, trauma, } \\
\text { blood transfusions, } \\
\text { infections, and } \\
\text { previous surgeries) }\end{array}$ & 0 and 1 & 1 & - & - & - \\
\hline $\begin{array}{l}\text { General physical } \\
\text { examination }\end{array}$ & 0 and $1^{c}$ & $1^{d}$ & - & 1 & A \\
\hline Weight measurement & 0 and 4 & 4 & - & 1 & B \\
\hline $\begin{array}{l}\text { Varicose veins } \\
\text { examination }\end{array}$ & - & - & - & - & - \\
\hline $\begin{array}{l}\text { Teeth and gums } \\
\text { examination }\end{array}$ & 0,1 and 2 & 1 & - & - & - \\
\hline $\begin{array}{l}\text { Nutritional needs } \\
\text { assessment or } \\
\text { providing } \\
\text { information about } \\
\text { them }\end{array}$ & 4 & $4^{\mathrm{e}}$ & - & 5 & A \\
\hline $\begin{array}{l}\text { Use of tobacco } \\
\text { assessment }\end{array}$ & 4 & 4 & 5 & 5 & A \\
\hline $\begin{array}{l}\text { Advice for reducing } \\
\text { sexually transmitted } \\
\text { infections, including } \\
\text { HIV }\end{array}$ & 0 and 4 & 4 & 5 & 5 & A \\
\hline $\begin{array}{l}\text { Child's health history } \\
\text { collection }\end{array}$ & - & 1 & - & - & - \\
\hline Pap Smear & 0 & 1 & - & 1 & B \\
\hline $\begin{array}{l}\text { Alcohol drinking } \\
\text { assessment }\end{array}$ & 0 and 4 & 1 & 1 & 1 & $\mathrm{~B}$ \\
\hline Offer HIV testing & 0 and 1 & 1 & 1 & 1 and 3 & $\mathrm{~B}$ \\
\hline Discussion about: & & & & & \\
\hline
\end{tabular}




\begin{tabular}{|c|c|c|c|c|c|}
\hline $\begin{array}{l}\text { Exercise pattern } \\
\text { (to avoid the risk } \\
\text { of falls or } \\
\text { injuries to the } \\
\text { abdomen and } \\
\text { recommenda- } \\
\text { tion of } 30 \\
\text { minutes of } \\
\text { moderate } \\
\text { activity) }\end{array}$ & - & 1 & - & 1 & $\mathrm{C}$ \\
\hline $\begin{array}{l}\text { Sleep pattern ( } 7 \\
\text { to } 9 \text { hours of } \\
\text { sleep per night) }\end{array}$ & - & - & - & 1 & c \\
\hline $\begin{array}{l}\text { Rest pattern (on } \\
\text { the left side of } \\
\text { the body to help } \\
\text { fetal circulation } \\
\text { and avoid fetal } \\
\text { distress and } \\
\text { putting a pillow } \\
\text { under the lower } \\
\text { back and legs) }\end{array}$ & 1 & - & - & - & - \\
\hline
\end{tabular}

${ }^{\mathrm{a}} 0=$ preconception; $1=$ first trimester $2=$ second trimester; $3=$ third trimester; $4=$ through the pregnancy; $5=$ time and frequency is not specified; $-=$ not mention it in the protocol.

${ }^{\mathrm{b}} \mathrm{A}$, consistent, good-quality patient-oriented evidence; B, inconsistent or limited-quality patient-oriented evidence; C, consensus, disease-oriented evidence, usual practice, opinion, or case series.

'Including heart, lung, thyroid, breast, liver, spleen, and lower extremities.

${ }^{\mathrm{d}}$ Including heart and lung.

${ }^{\mathrm{e}}$ Identifying the barriers to adequate nutrition. 
Table 3. Comparison of Clinical Tests and Prenatal Screening ${ }^{\mathrm{a}, \mathrm{b}}$

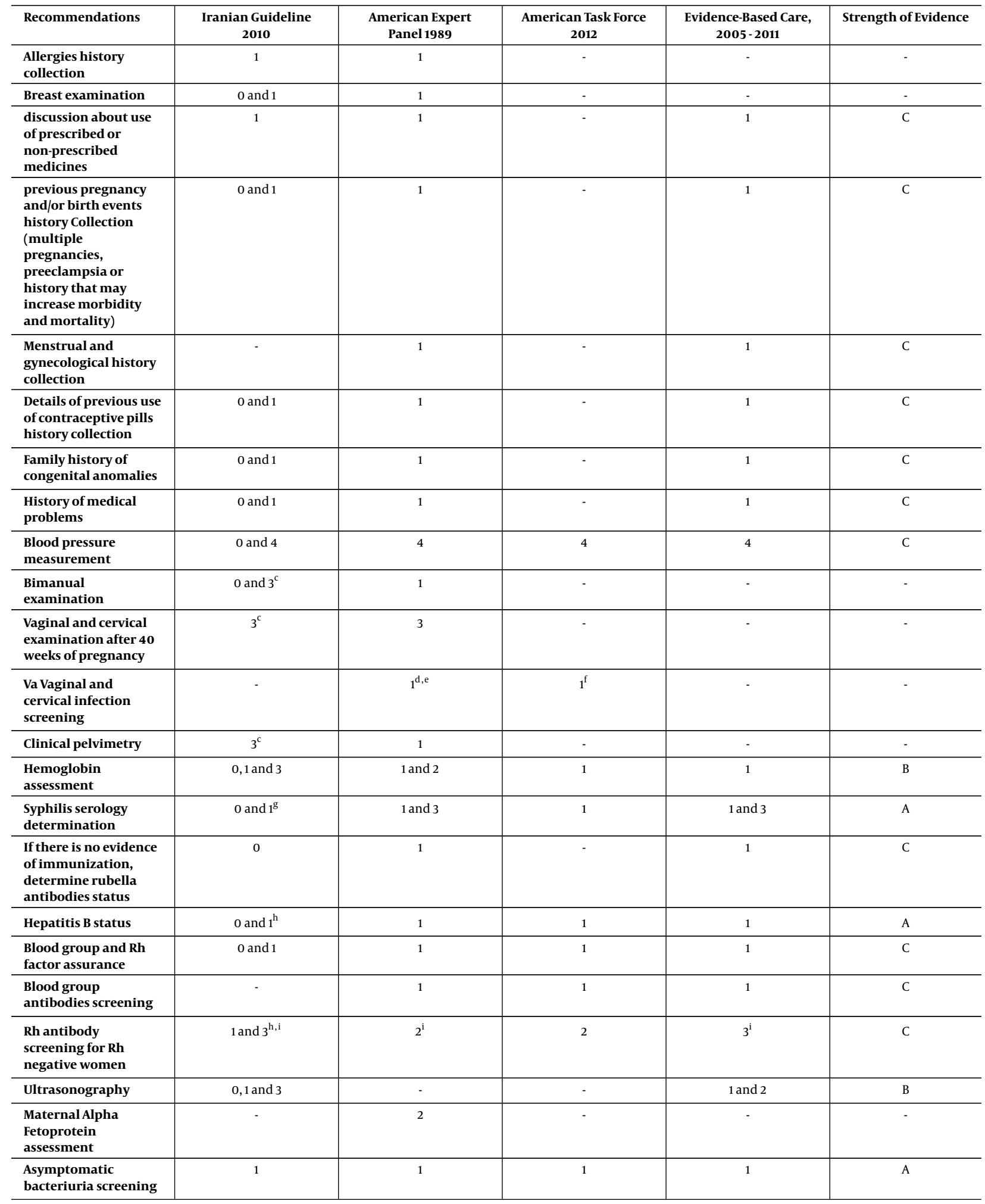




\begin{tabular}{|c|c|c|c|c|c|}
\hline $\begin{array}{l}\text { Gestational diabetes } \\
\text { Screening }\end{array}$ & $1^{\mathrm{j}}, 3$ & 2 & $2^{j}$ & $2^{\mathrm{h}}$ & $\mathrm{C}$ \\
\hline $\begin{array}{l}\text { Group B Streptococcus } \\
\text { screening }\end{array}$ & - & - & - & 3 & $\mathrm{C}$ \\
\hline $\begin{array}{l}\text { Urine analysis for } \\
\text { nitrates }\end{array}$ & 0,1 and 3 & - & - & - & - \\
\hline $\begin{array}{l}\text { Urine analysis for } \\
\text { glucose }\end{array}$ & 0,1 and 3 & 1 & - & 4 & $\mathrm{C}$ \\
\hline $\begin{array}{l}\text { Urine analysis for } \\
\text { specific gravity }\end{array}$ & 0,1 and 3 & - & - & - & - \\
\hline $\begin{array}{l}\text { Urine analysis for } \\
\text { protein }\end{array}$ & 0,1 and 3 & 1 & - & 4 & $\mathrm{C}$ \\
\hline $\begin{array}{l}\text { Palpation of the } \\
\text { abdomen to assess the } \\
\text { uterine }\end{array}$ & $3^{c}$ & - & - & 4 & B \\
\hline $\begin{array}{l}\text { Palpation of the } \\
\text { abdomen to assess the } \\
\text { fetal presentation }\end{array}$ & $3^{c}$ & 2 and 3 & - & 3 & B \\
\hline $\begin{array}{l}\text { Palpation of the } \\
\text { abdomen to assess } \\
\text { fetal growth or Uterus } \\
\text { height }\end{array}$ & 2 and 3 & 2 and 3 & - & 4 & B \\
\hline $\begin{array}{l}\text { The number of fetal } \\
\text { movements count }\end{array}$ & - & - & - & $4^{\mathrm{k}}$ & A \\
\hline $\begin{array}{l}\text { Fetal heart sounds } \\
\text { Listening }\end{array}$ & 2 and 3 & 2 and 3 & - & 4 & C \\
\hline $\begin{array}{l}\text { Cervix checking after } \\
40 \text { weeks of } \\
\text { pregnancy }\end{array}$ & $3^{c}$ & 3 & - & - & - \\
\hline $\begin{array}{l}\text { Screening for } \\
\text { trisomies } 13,18 \text {, and } 21 \\
\text { using multiple tests }\end{array}$ & - & - & - & 1 and 2 & C \\
\hline
\end{tabular}

${ }^{\mathrm{a}} 0=$ preconception; $1=$ first trimester; $2=$ second trimester; $3=$ third trimester; $4=$ through the pregnancy; $5=$ time and frequency is not specified; $-=$ not mention it in the protocol.

${ }^{\mathrm{b}} \mathrm{A}$, consistent, good-quality patient-oriented evidence; B, inconsistent or limited-quality patient-oriented evidence; C, consensus, disease-oriented evidence, usual practice, opinion, or case series.

${ }^{\mathrm{c}}$ At the hospital.

${ }^{\mathrm{d}}$ Gonorrhea screening.

${ }^{\mathrm{e}}$ Chlamydia screening for women in endemic or high risk groups.

${ }^{\mathrm{f}}$ Chlamydia screening for adolescents and women in high risk groups.

${ }^{\mathrm{g}}$ In women in high risk groups.

${ }^{\mathrm{h}}$ Unsensitized Rh-negative women should receive Rh immune globulin at 28 to 34 weeks of pregnancy, or in any bleeding situation such as abortion, mole, etc.

${ }^{\mathrm{i}}$ Unsensitized Rh-negative women should receive Rh immune globulin if the baby is Rh-positive.

${ }^{\mathrm{j}}$ In high risk women including age > 25 years, obesity: BMI > 30, ethnicity: Hispanic, Asian, African-American, family history: first degree relative, and previous GDM.

${ }^{\mathrm{k}}$ Should not be done.

${ }^{1}$ They are not recommended without prior non-invasive screening except for women $\geq 40$ years at expected date of delivery, women at risk of having a baby with chromosomal abnormalities (Down syndrome or trisomy 18 or have a personal or family history or women who had ICSI for getting pregnant) and women with multiple gestations who are $\geq 35$ years old at expected date of delivery. 